\title{
Exploring factors affecting undergraduate medical students' study strategies in the clinical years: a qualitative study
}

\author{
Hanan M. F. Al Kadri • Mohamed S. Al-Moamary • Margaret Elzubair • \\ Mohi Eldien Magzoub - Abdulrahman AlMutairi • Christopher Roberts • \\ Cees van der Vleuten
}

Received: 18 August 2010/Accepted: 17 December 2010/Published online: 5 January 2011

(C) The Author(s) 2011. This article is published with open access at Springerlink.com

\begin{abstract}
The aim of this study is to explore the effects of clinical supervision, and assessment characteristics on the study strategies used by undergraduate medical students during their clinical rotations. We conducted a qualitative phenomenological study at King Saud Bin Abdulaziz University for Health Sciences, College of Medicine, Riyadh, Saudi Arabia during the period from November 2007 to December 2008. We conducted semistructured focus groups interviews with students and conducted individual interviews with teachers and students to explore students' and clinical teachers' perceptions and interpretations of factors influencing students' study strategies. Data collection was continued until saturation was reached. We used Atlas-ti Computer Software (Version 5.2) to analyse the data, apply the obtained themes to the whole dataset and rearrange the data according to the themes and sub-themes. Analysis of data from interviews with twenty-eight students and thirteen clinical supervisors yielded three major themes relating to factors affecting students' study strategies: "clinical supervisors and supervision", "stress and anxiety" and "assessment". The three themes we identified played a role in students' adoption of different study strategies in the "community of clinical practice". It appeared that teachers
\end{abstract}

H. M. F. Al Kadri $(\square)$ · M. S. Al-Moamary

Clinical Affairs Department, College of Medicine, King Saud Bin Abdulaziz University for Health Sciences, King Abdulaziz Medical City, PO Box 57374, Riyadh 11574, Saudi Arabia e-mail: halkadri@gmail.com

M. Elzubair · M. E. Magzoub

Medical Education Department, College of Medicine, King Saud Bin Abdulaziz University for Health Sciences, Riyadh, Saudi Arabia
A. AlMutairi
Department of Radiology, King Saud Bin Abdulaziz University for Health Sciences,
King Abdulaziz Medical City, Riyadh, Saudi Arabia
C. Roberts
Sydney Medical School-Northern, University of Sydney, Sydney, NSW, Australia
C. van der Vleuten
Department of Educational Development and Research, Faculty of Health, Medicine and Life
Sciences, University of Maastricht, Maastricht, The Netherlands 
played a key role, particularly as assessors, clinical supervisors and as a source of stress to students.

Keywords Study strategy · Assessment - Clinical supervisor - Clinical attachment . Anxiety

\section{Introduction}

Learning style inventories initially emphasized the relative stability of students' study strategies. They were used to predict students' future academic performance (Biggs 1970, 1976; Entwistle and Entwistle 1970; Schmeck et al. 1977). Based on the early inventories, it was found that students' study strategies reflected three basic learning models (Broadbent 1966): surface learning, involving "repetition of analyses already carried out" and usually directed at reproducing information; deep level learning, using "a greater degree of semantic or cognitive analysis" usually aimed at gaining insight and understanding and "assessment driven category", named a strategic approach to studying (Entwistle and McCune 2004).

Further research on students' study approaches has focused more on the effect of teaching-learning environment (Biggs 1999). It investigated the differing ways students interpret the requirements of a task within a specific learning context (Marton and Saljo 1997). Students' study approaches were then found to be unstable. More recent inventories have emphasized students' self-conscious reflection on studying, drawing on the ideas of "metacognition" and "self-regulation" (McKeachie 1990; Vermunt 1996, 1998). Categorizations of students' study approaches were then modified to a deep, reflective and elaborate approach and superficial with serial, reiterative, or rehearsal approach. A third approach of studying that describes methodical, well-organized studying linked to effort and achievement motivation was added replacing the strategic approach to learning.

Several factors have been shown to influence undergraduate students' study approaches, with students adopting strategies in accordance with their interpretations of the requirements of the tasks assigned within a specific learning environment (Marton and Saljo 1997). These interpretations varied depending on students' perception of the academic quality of a course and the nature of the curriculum (Richardson et al. 2007), students' implicit theories of learning on entering higher education (Edmunds and Richardson 2008) and the learning environment to which students are exposed (Reid et al. 2005). However, these interpretations alone do not explain the full range of students' intentions and motivations with respect to studying (Mattick and Knight 2007). Students' perceptions of the environment in which they learn and are assessed also interfere with their choice of the study approaches. However, it is hard to predict which choices students will make (Mattick and Knight 2007, 2008). It appears that there is a variety of factors influencing how students tackle their academic work. These factors can lead to swings in students' appraisals of the usefulness of different study approaches.

When students start clinical training, during which they gain experience and skills by taking part in the provision of patient care, they encounter different supervised learning environments and different assessment programs. They are also exposed to stressful situations where patients' safety is a major issue (Kennedy et al. 2009). In this learning environment, supervisors' knowledge, skills, encouragement of a problem-solving approach, critical reflection on practice and the way they supervise students are perceived 
as important factors affecting students' learning and study approaches (Marrow and Tatum 1994).

Most assessment in the clinical workplace is directed at different levels of Miller's Pyramid (Miller 1990). In addition to knowledge, students are assessed on their ability to perform specific skills in clinical practice. Ideally, assessment in the clinical years should focus on students' ability to organize thoughts, link theoretical knowledge to patients' management, communicate with patients and the environment and elaborate on patients' conditions. It should also focus on students' clinical skills and work.

Deep-learning approaches, including knowledge integration, writing summaries and self-testing (Groves 2005; McParland et al. 2004; Newble and Clarke 1986) are important to prepare students for assessment, clinical problem solving and safe patient management. However, since students are known to swing between different study strategies in response to different environmental and contextual factors, they may occasionally use strategies involving "memorizing without understanding" (Meyer 2000) and "fragmented knowledge" (Meyer 1991).

From the above, it is clear that learning functions play a central role in the theory on regulation of learning processes (Vermunt 1989). However, little is known about the manner in which students carry out and regulate these functions in a clinical educational context. Insight into these processes can make an important contribution to the improvement of clinical education and its instructional process. In the clinical years, we expected to find a spectrum of students' responsiveness to stressful situations, in terms of study strategies, such as dealing with patient problems, assessment and clinical supervision. A question with important implications for teaching and learning then arises: under which conditions do students use which study strategies? And furthermore, which factors contribute to students' use of particular strategies? To our knowledge, no study has specifically explored this issue within the clinical learning environment. The increasing need for information on training and certification in higher education and the increasing requirements of universities to justify effectiveness and efficacy of their teaching put more importance to the answers of these questions.

In this work, we have addressed two research questions: (I) what are the effects of clinical supervision, patient encounters and assessment characteristics on the study strategies adopted by medical students? and (II) can these factors be classified as promoting one of the different known study strategies?

\section{Methods}

The study was conducted at King Saud Bin Abdulaziz University for Health Sciences (KSAU-HS), College of Medicine (COM), Riyadh, Saudi Arabia between November 2007 and December 2008. The College accepts only male students and is housed within King Abdulaziz Medical City, a 900-bed tertiary care centre. KSAU-HS offers a 4 year graduate entry program with an integrated, problem-based learning (PBL) curriculum adopted from the University of Sydney.

\section{Assessment of clinical blocks}

The clinical years (years 3 and 4) of the Undergraduate Medical Program consist of five different clinical blocks. Within each clinical block, students rotate in different clinical attachments and are assigned to supervisors responsible for clinical training and 
assessment. The term "clinical supervisor" refers to experienced clinicians, who implement the curriculum objectives and are responsible for patients' protection and safety while providing professional support and teaching to students. Their role also includes helping individual students to develop knowledge and competence and assume responsibility for their own practices.

At KSAU-HS, students accompany their clinical supervisors throughout their daily clinical activities and the supervisors assign students tasks that are in alignment with the curriculum objectives. These tasks are performed under direct supervision of supervisors or senior team members, as students are not allowed to conduct clinical encounters unsupervised. When students rotate to another clinical attachment within the same block, they change supervisors and clinical exposure.

The assessment program for the clinical years is block-based. At the end of each clinical attachment, students meet with their clinical supervisor for verbal and written qualitative formative assessment and feedback. Clinical supervisors are responsible not only for formative but also for summative assessments, both of which should reflect students' performance during the clinical attachment. In this paper, we use the term "summative assessment" with reference to assessment contributing to course grades, while "formative assessment" refers to assessment as a tool to aid the learning of students but without grading. During each clinical block, students are given one summative long case exam and one mid-block summative multiple choice (MCQ) exam, while the end-of-block assessment consists of a summative MCQ exam, a summative objective structured clinical examination (OSCE) and a summative MCQ exam on data interpretation. The MCQ exams are mostly composed of type A questions aimed at assessing the "knows how" level of Miller's pyramid. Assessment of students' clinical performance during all attachments within a block counts for $40 \%$ of the final block grade, while the final exam is worth the remaining $60 \%$.

\section{Participants}

We conducted semi-structured interviews (Creswell and Miller 2000; Ashworth and Lucas 2000; Ritchie and Spencer 1994) because this type of interview provides more freedom to obtain a complete picture of participants' experiences.

By way of purposeful sampling, we invited students who had experienced the clinical blocks and the related assessments and the clinical supervisors of the different blocks to participate in the study. We performed seven semi-structured focus group interviews in groups of four students to achieve greater variation in the discussion and elaboration on students' lived experiences. Occasional conflicts among students enriched the data, which led to deeper discussions and more varied opinions. The participants were 28 out of the total of 61 students in the third and fourth years of the study program. We also conducted semi-structured individual interviews with 13 out of 44 clinical supervisors. The thirteen clinical supervisors were randomly selected from the pool of clinical supervisors who all agreed to participate. The purpose of using individual interviews was to allow the teachers to speak openly and without restrictions or bias. Open-ended interview questions similar to those used with the students were used to probe the teachers' views on students' study strategies and the factors which influenced their strategy selection (Appendix). Interview schedules included some open core questions and a number of suggestions for continuation questions. Questions were asked about the methods used by the students when studying the course materials, the role of the teachers in their studies, the factors affecting the way the students study, views on studying at the university, study expectations and study plans and 


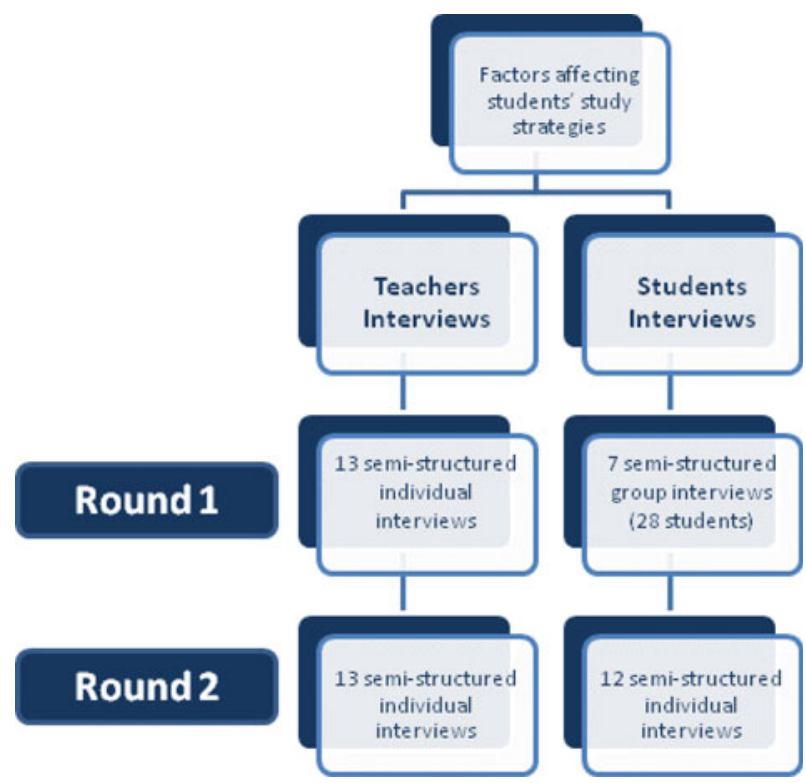

Fig. 1 Diagram representing the two rounds of the research conduction

the supervisors' roles in patients' encounters and assessment. For triangulations of the data, we conducted a second set of interviews with all of the thirteen clinical teachers and twelve of the students who had participated in the focus groups. They were asked about their opinions on the results of the first round of students' focus group interviews (Fig. 1). Students' reported study approaches and related factors were the focus of these interviews. The themes derived from the initial analysis were used to create further interview questions for a more in-depth individual exploration of the reasons for the students' lived experiences. The KSAU-HS, COM Research Ethics Committee approved the study.

\section{Data collection}

All interviews were conducted by the principal investigator and a research assistant. Both students and teachers were allowed to talk freely and express their opinion on the effects of clinical supervision, patient encounters and assessment characteristics on students' adopted study strategies. We appreciated the presence of complex relationships between students' different study strategies and their teaching and learning environment; therefore, we decided to choose the phenomenographical approach.

Phenomenography is a research methodology that can be used to map the qualitative different ways people experience, conceptualize, perceive and understand phenomena (Marton 1986). The objective of this method is to frame and describe these qualitative differences in conceptual categories. The phenomenographic approach has been used in various educational research contexts and with various populations (Marton 1986; Pramling 1990; Vermunt 1996). We examined qualitatively the different ways by which students approach their studying in response to different stressful conditions. Our assumption was that different students perceive clinical exposure and direct patients encounter, clinical assessment, supervisors and supervision differently (Marton 1986). We 
aimed to understand the similarities and differences between students' perceptions (Svensson 1997) and the relationship between these differences and students' learning strategies.

The themes of the interviews and focus groups were summarised and presented to the participants for feedback and reactions. The researchers' field notes, debriefing notes and the verbatim transcriptions of all the interviews and focus groups were integrated. This process was repeated for the second set of interviews. Each focus group session lasted 45-90 min and the individual interviews lasted for 30-45 min.

Data analysis

All interviews were transcribed verbatim and read completely. Subsequently, the principal investigator studied the interviews several times. Themes and sub-themes relevant to the research questions were assigned and representing quotes were selected. This process was repeated for each interview in order to capture the full breadth and diversity of the students' and teachers' views and experiences (Ritchie and Spencer 1994). Similarities and differences were determined. Themes and sub-themes (codes) were then refined and finalized. In order to improve the credibility and transferability of the data, we used member checking whereby two of the authors, HK and MM, compared the themes and codes resulting from the analyses of 3 students' and 3 teachers' interviews and discussed differences until they reached a consensus (Creswell and Miller 2000; Polit and Beck 2003). Occasionally, students elaborated on their experiences during the pre-clinical years (phase I) or even their previous study. The data was considered as confounder and was not included in the research. The Computer Software Atlas-ti (Version 5.2) was used to apply the themes to the whole dataset and to rearrange the data according to themes and subthemes.

\section{Results}

We invited 56 out of a total of 61 students (clinical years 3 and 4) to participate in the study. Twenty-eight of these students participated voluntarily (50\% response rate). The students' mean age was (26.74) years, and their mean graduation GPA was (3.96/5). These characteristics are similar to the mean age (26.77 years) and the mean GPA at the graduation time $(3.89 / 5)$ of the non participant students. The analysis revealed three major themes in relation to factors affecting students' study strategies: "clinical supervisors and supervision", "stress and anxiety" and "assessment" (Table 1). We presented the themes with illustrative quotes from interviews with students (S) and teachers (T).

Clinical supervisors and supervision in a clinical context

Students indicated that their learning strategies were strongly influenced by supervision, particularly when they felt it was constructive. Students appreciated effective workplace supervision, and indicated that it had a positive impact on their study strategies. Constructive supervision helped students to integrate clinical knowledge into clinical practice, summarise patients' histories and solve patients' problems. Teachers as role models, their way of coaching and guiding students, their experience and their commitment to clinical teaching were identified as crucial factors in enhancing the quality of learning in the workplace. According to the students, there was a relationship between students' 
Table 1 Various themes and codes relating to factors affecting students' study strategies in a clinical context

\begin{tabular}{ll}
\hline Themes & Codes \\
\hline Clinical supervisors and supervision & Constructive supervision \\
& Role modelling \\
& Teaching time \\
& Teaching experience \\
& Teachers' motivation \\
& Faculty development \\
& Overestimation of students' \\
Stress and anxiety & Unjectives \\
& Assessment method \\
Assessment & Assessment weight \\
& Assessment time \\
& Fair assessment \\
\hline
\end{tabular}

motivation, teaching and study strategies. Direct supervision was a strong motivator for students to use deep learning strategies. Supervisors who showed a flexible attitude towards students and their knowledge stimulated students to use a focused study strategy and a deeper approach to learning. The availability of experienced and motivated supervisors who support direct patients' encounter made students more interested in critically analysing patients' clinical conditions, read about them and utilize this work to formulate management plans. Some of the students related the way they tackled their patients' clinical problems to their supervisors, saying, "It depends on whom I rotate with, who my supervisor is and who assesses me,... this may encourage me to study and read more" and "...to show me how to read, what to follow and....then.. ok he can... he can say go by yourself..." (S). Thus, teachers' availability and teaching experience were important factors in the selection of students' study approach. According to the teachers, their workload needed to be redistributed to make them available for direct supervision. The role of the college was emphasised in this regard. Teachers felt that a good balance between clinical work and teaching encouraged them to involve students in patient management and increased students' interest in clinical training "more time spent with patients, makes them keen to learn" (T). Due to the conflict between clinical teachers' assignment as clinicians and their duties as clinical teachers, their work arrangement appears to be difficult to achieve. Teachers recommended that all their clinical and academic assignments come from one direction. "The college should assign teachers' workload and not the clinical departments" (T).

Students reported that patient encounters boosted their confidence in performing physical examinations and led to gains in clinical experience. Direct contact with patients stimulated the students to approach their learning deeply. They were more capable of integrating their theoretical knowledge into clinical practice and elaborating on their patients' conditions. The studied teachers have supported the same idea, "The most important trigger for students to learn is their new experience in the hospital. The resulting excitement...stimulates them to do more reading and preparation for assessment", (T) and "clinical attachment, the more cases I see the better. I go home and read about the disease and try to gather all relevant information about it" (S).

When supervision was disorganized and not constructive, many clinical activities of the students went unsupervised and students became frustrated and lost interest in clinical 
training. This had a negative effect on their studies. Students in this case opted to utilize the reiterative and rehearsal method for reading. They read from lecture slides and previous students' notes. The unavailability of supervisors' time and motivation led to their superficial approach to learning. "How can he assess our efforts? He didn't show up and he did not see us at all...I would rather stay at home and read..." (S). It was difficult for teachers to find time for teaching in their busy clinical schedules. As a result, the amount of time devoted to teaching depended mainly on teachers' motivation and willingness to teach. Variability in attention of supervisors led to variability in students' approaches to learning. Students' narratives were consistent with a deep approach to their learning in the presence of increased systematic clinical supervision. "...we work in a busy department; we don't have much time assigned to students...", (T) and “...there are tutors who love to teach and devote time to teaching and some just don't", (T) and "Yes, we usually focus during the clinical attachments and make a real effort to learn from our supervisors. Their presence gives us a lot of motivation to use the time dedicated for the clinical attachment to learn. But some supervisors don't show up, arrive late or leave immediately after rounds ..." (S).

Teachers became more interested in teaching when they identified teaching competencies that needed to be improved. They saw faculty development activities to improve their teaching skills as major factors, which could indirectly improve students' study strategies “... to improve student learning, supervisors' teaching skills should be improved first” (T).

Stress and anxiety

Students indicated that supervisors could be a potential source of stress and anxiety; for instance when supervisors over-estimated their clinical abilities, asking them to answer questions or perform tasks that went beyond the curriculum objectives. This was even more stressful when it happened in front of a patient or a colleague. Stress and anxiety led to intermittent, unfocused reading and a superficial approach to learning. Occasional unavailability of supervisors at the workplace was another source of stress for students, especially since the students were dependent on supervisors for their final marks. Students felt it was unfair to be assessed by someone who was not quite familiar with their performance. To avoid stress and embarrassment, students start to speculate on the possible tasks or questions that they might be asked by their supervisors and try to prepare for them. This results in rehearsal of sporadic and disorganized reading. "Our supervisors should orient their teaching to the curriculum objectives. They should be familiar with the required levels. I think some of them expect us to perform at the level of a resident" (S) and "we have to read for the exam, we have to read for the clinical attachment, this is the problem..., how can I get time in between to read, I am always under stress..." (S) and "how can I meet the entire objectives in three months? So we are under stress. I tried to read from here and there... If without stress,... I can organize myself; schedule my topics, my objectives ..." (S).

\section{Assessment}

Opinions about the impact of different assessment methods (OSCE, long case, etc.) on students' study strategies differed. Some students said that assessment methods did not affect how they prepared for exams, but some other students said they were affected by assessment methods, "I will be prepared regardless of the exam method" (S) and "The 
assessment method affects how I study" (S). Students' opinions differed from those of the majority of the teachers. Teachers thought that all students were exam oriented and used assessment strategically to achieve their goals.

Some students mentioned that they modified their study strategies based on the weighting of the subject and how much time was assigned for reading "...... as students, we organise our study agenda based on the exam schedule and assessment methods" (S). As a result, students sometimes adopted superficial strategies trying to read all possible information that might come in the exam without relating it to a patients' management plan. They opt to guarantee a pass or even high marks by mimicking what looks like an achievement motivation study strategy "... we are doing surgery, I have consulted my friends ... and I know some interns. I selected the best book on surgery and read it from a to z. I read each day ten pages till I covered it all ..." (S). Despite these differences, there was congruence between students and teachers in their identification of exam marks as a main influence on study strategies. Students acted as "mark hunters" using variable strategies (deep, superficial, and to a higher extent an effort management strategy). They aimed at passing the exam or scoring high marks "I just work hard because I just want to get an A" (S).

The sub-theme of a "fair assessment" was derived from views expressed by both students and teachers. It was described as a well-designed assessment aimed at students' true level of training and in alignment with curriculum objectives. It gave students a sense of security and was an important factor in encouraging them to study deeply. Properly designed blue printing and linkage of assessment to the curriculum objectives was one of the characteristics (of fair assessment), "final exam should reflect all the curriculum components in a fair distribution percentagewise" (T) and "if assessment items are not too precise, it's difficult for assessors to decide on the mark, is it one or two, two or three, one or zero" (T). Assessment that reflects curriculum objectives promotes students' satisfaction and affects students' study approach. It guides students while studying based on these objectives. However, that will be towards effort management strategy. Hence, the way we structure our curriculum objectives will have a major effect on students' study approach "I follow the objectives, ... why I follow them?.... because I always think about the final exam." (S).

\section{Discussion}

In the clinical context, students' knowledge about their training requirements, their assessment and their supervision created a common ground for students' learning, guided their study strategies and gave meaning to their actions and interactions. The presence of a community of students and supervisors in the clinical context created the social fabric of students' learning, relations with the surroundings and their interrelations.

The term "community of practice" was first described by Lave and Wenger (1990) as learning through practice and participation. It describes the function of a group of people who have a variety of experiences but share an interest or a profession. They share information and experiences, learn from each other, and have similar opportunities to develop (Lave and Wenger 1990). Everybody is involved in a number of communities of practice whether at work, school, or home. Their structural characteristics are defined as a domain of knowledge, a notion of community and a practice (Wenger 1998).

It appears that the studied students' learning in the clinical context and their social experiences are a new example of "community of practice" that can be called "community of clinical practice". In this research, we have evaluated students' actions and interactions in the "community of clinical practice" and their effect on their study strategies. We then 
reached in our evaluation Kirkpatrick's second level of learning evaluation model (Kirkpatrick 1994) (Fig. 2). In the "community of clinical practice", students are brought together by joining common clinical and educational activities and by what they have learned through their mutual engagement in these activities (Wenger 1998). In this context, students had to generate and prepare a shared repertoire of ideas and commitments. They had to share ways of doing and approaching tasks. The studied students' ongoing activities and their involvement in "community of clinical practice" manipulated their learning strategy approach (Lave and Chaiklin 1993). Students' clinical training resulting stress, clinical supervisors and supervision and the implemented assessment were identified as factors affecting students' study strategies. Depending on whether these factors have a negative or positive impact on the learning environment, students' study strategies can become increasingly surface oriented, swing between surface, deep, effort and achievement motivation or reflect a deep learning strategy (Fig. 2). This is consistent with evidence in both medical and non-medical disciplines (Groves 2005; Ramsden and Entwistle 1981; Schmidt et al. 2010; Seabrook 2003).

A teacher's personality, availability and effectiveness as a role model in the "community of clinical practice" influenced how students studied. On the whole, the supervisory practice of clinical teachers strongly influenced the way students studied. Students placed great value on the availability of supervisors to provide guidance and coaching. While availability enhanced skill acquisition, lack of supervision deprived students of essential educational support, thereby creating a potential source of stress. Findings from other studies lend support to factors identified by the teachers and students in this study. The absence of supervisors can also lead to a loss of the effect of role modelling (Kennedy et al. 2009) and can increase the likelihood of students practising surface or strategic approaches to learning (Gray et al. 2008).

Teachers' methods of presenting information to students, their supervisory skills (Biggs 1999), their skills in activating clinical reasoning and their ability to motivate students have all been identified as major factors in determining students' study strategies (Diemers et al. 2008; Entwistle and McCune 2004). Furthermore, well trained teachers have been shown

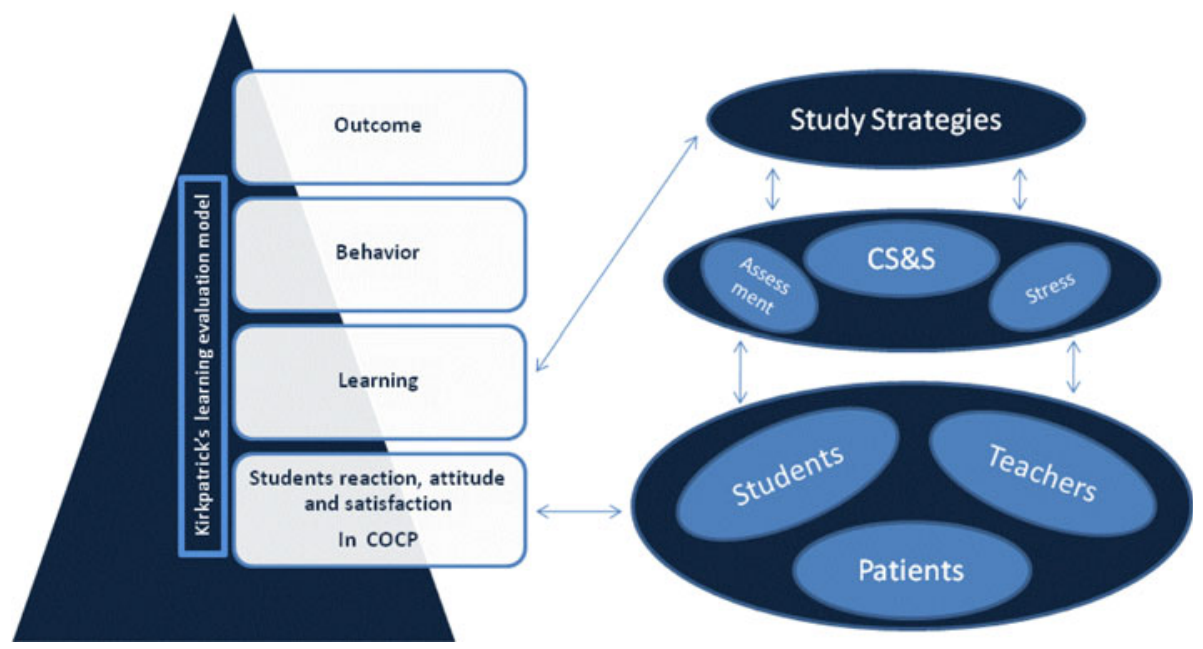

Fig. 2 Evaluation of factors affecting students study strategies in the "community of clinical practice". COCP Community of clinical practice, $C S \& S$ Clinical supervisors and supervision 
to be more interested in direct supervision during patient encounters (Diemers et al. 2008). Here lies the importance of teachers' professional development, which can lead to more competent, satisfied, motivated and reliable teachers (Bland et al. 2002). It has been shown that properly trained teachers are better equipped to provide less structured flexible clinical teaching. This facilitates students' transition from preclinical to clinical training and its related "community of clinical practice" issues, motivates the students to learn and helps them to modify their professional behaviour through utilizing their teachers' feedback (Diemers et al. 2008; Fry 1993).

Our results with regard to available time for teaching are also confirmed by other studies, which have reported variations between institutions and teachers in the acceptance of responsibility for clinical teaching and the time allocated for supervision (Hayes 2008; Wimmers et al. 2006). In our study, limited time for clinical teaching was regarded as a barrier to high quality teaching practice, with some of the teachers saying they needed protected time for teaching while others were not prepared to allocate more time for teaching. The variation in teachers' perception of time needed to transmit knowledge and practice in the domain of "community of clinical practice" reflects their variation in interest, interaction and sense of responsibility.

Due to factors in the setting of our study, the results offer no insights into the role of supervisors in ensuring patient safety and alleviating students' stress. Because the students were not allowed to engage in patient contacts without supervision, stress related to unsupervised patient encounters and its effects on study strategies could not be studied (Kennedy et al. 2009). However, there were other types of stress experienced by students, notably stress related to teachers combining the supervisory role with responsibility for assessment. This interaction promoted patchy reading and surface or strategic plans to the detriment of deep study strategies, thereby creating a hidden curriculum (Al Kadri et al. 2009).

Most students and teachers perceived assessment as a major influence on the way students prepared for exams. This is not surprising based on the generally accepted view that clinical exams should be more than tests of factual knowledge. Students need good knowledge as well as the ability to apply that knowledge to any given task or clinical scenario. Encouragement of appropriate application of clinical knowledge can foster a deep approach to learning and enhance performance on clinical assessments (Norton 2004). Timing and weight of exams influenced students' study strategies, which confirm that students use deep, strategic and surface approaches variably, depending on perceived challenges of the learning environment. Similar variation was reported in other studies (Groves 2005; Papinczak 2009).

There are several limitations to this study. This research has evaluated the first two levels of Kirkpatrick's learning and training evaluation (students' reaction and their learning in the clinical context). To evaluate the third and fourth levels (Kirkpatrick 1994; Phillips 1996), further research is required. This will enable us to understand the continuous interaction among students, teachers, education environment and patients' care and satisfaction. Moreover, the results may be uniquely applicable to the medical school where it was conducted. However, by including the main stakeholders and using a clear methodology we aimed to give a clear unbiased example on students' learning behaviour in one of the "communities of clinical practice". To assess different behaviour in different environments, and different genders further research is needed. Some might raise the question whether it would not have been preferable to explore learning strategies in specific clinical specialities rather than across all clinical blocks. They may be right in arguing that factors observed in one context may be different in another one. We think 
this should be a subject for further research. Moreover, our study design was limited to students' and teachers' views and experiences and did not include the relationship between learning strategies and students' outcomes. A relatively recent study from the Netherlands found no significant relationships between learning strategies and clinical performance (Van Lohuizen et al. 2009), but we acknowledge that this is an important area for further work.

\section{Conclusion}

In an educational clinical context, it was found that students' social interactions affect their studying approach. This social and clinical education environment represents a new example of the community of practice theory, we named it: "community of clinical practice". In this community, we identified factors with potential negative and/or positive effects on the likelihood of students adopting different learning strategies. In the community of clinical practice, teachers played a crucial role, particularly in assessment and clinical supervision and can be a potential source of stress to students. They were unaware of the potential negative and positive consequences of their actions as supervisors and assessors with regard to students' learning strategies. Awareness enhancement through an effective faculty training program is required to promote desired students' study strategies. Further promotion of desired study strategies can be obtained through clinical curriculum modification. The emphasis should be on more supervisors and supervision role, more clinical involvement, more clinical assessment and constructive alignment.

Acknowledgments The principal investigator would like to thank Professor Ali Hajeer for his time and effort in reviewing the academic writing of this manuscript. Moreover, the authors wish to thank the students and clinical supervisors who participated in this study for their time and willingness to share their experiences and insights.

Open Access This article is distributed under the terms of the Creative Commons Attribution Noncommercial License which permits any noncommercial use, distribution, and reproduction in any medium, provided the original author(s) and source are credited.

\section{Appendix: Factors affecting students' study strategies}

Semi-structured interview questions

1. Can you please describe to me which block or rotation you are currently in?

2. What are the clinical activities you are expected to perform in this block?

3. In addition to this, what other structured learning activities do you take part in?

4. How do you usually study? What factors may affect (change) your way of studying? Why?

5. What do you think of your clinical supervision? What about your supervisors? What about your team? How did this affect your studying? So what improvements might make you focus more on your patients' management?

6. What is your assignment within the clinical team? How do you tackle your patients' problems? 
7. What about stress when you started the clinical training? How do you deal with it, if any? Will this affect your studying?

8. What assessments have you undergone so far this year?

9. So how do you prepare for these various assessment activities? Do you use different strategies (ways) for different assessments? Can you give me an example of the strategies (ways) that you would use?

10. What kind of things influence what you read or do in preparation for the various assessments?

11. What do you think of your assessment? What do you think of its fairness?

12. What about the alignment or link between the structured teaching and learning program and assessment? How will this affect your studying or the way you study?

13. What do you think of the timing of your assessments? What about the different weightings given to each? Does this affect the way you study?

\section{References}

Al Kadri, H. M., Al-Moamary, M. S., \& van der Vleuten, C. (2009). Students' and teachers' perceptions of clinical assessment program: A qualitative study in a PBL curriculum. BMC Research Notes, 2, 263.

Ashworth, P., \& Lucas, U. (2000). Achieving empathy and engagement: A practical approach to the design, conduct and reporting of phenomenographic research. Studies in Higher Education, 25(3), 295-308.

Biggs, J. B. (1970). Faculty pattern in study behaviour. Australian Journal of Psychology, 22, 161-174.

Biggs, J. B. (1976). Dimensions of study behaviour: Another look at a.t.i. British Journal of Educational Psychology, 46, 68-80.

Biggs, J. (1999). Teaching for quality learning at university. Buckingham: SRHE and Open University Press.

Bland, C. J., Seaquist, E., Pacala, J. T., Center, B., \& Finstad, D. (2002). One school's strategy to assess and improve the vitality of its faculty. Academic Medicine, 77, 368-376.

Broadbent, D. E. (1966). The well-ordered mind. American Educational Research Journal, 3, $281-295$.

Creswell, J. W., \& Miller, D. L. (2000). Determining validity in qualitative inquiry. Theory Into Practice, 39(3), 124-130.

Diemers, A. D., Dolmans, D. H., Verwijnen, M. G., Heineman, E., \& Scherpbier, A. J. (2008). Students' opinions about the effects of preclinical patient contacts on their learning. Advances in Health Sciences Education: Theory Practice, 13(5), 633-647.

Edmunds, R., \& Richardson, J. E. (2008). Conceptions of learning, approaches to studying and personal development in UK higher education. British Journal of Educational, 79, 295-309.

Entwistle, N. J., \& Entwistle, D. M. (1970). The relationships between personality, study methods and academic performance. British Journal of Educational Psychology, 40, 132-141.

Entwistle, N., \& McCune, V. (2004). The conceptual bases of study strategy inventories. Educational Psychology Review, 16(4), 325-345.

Fry, A. W. (1993). Capturing the complexity of clinical learning environments with multiple qualitative methods. Evaluation and the Health Professions, 16(1), 44-60.

Gray, C. S., Hildreth, A. J., Fisher, C., Brown, A., Jones, A., Turner, R., et al. (2008). Towards a formative assessment of classroom competencies (FACCs) for postgraduate medical trainees. BMC Medical Education, 8, 61 .

Groves, M. (2005). Problem-based learning and learning approach: Is there a relationship? Advances in Health Sciences Education, 10, 315-326.

Hayes, R. (2008). Assessment in medical education: Roles for clinical teachers. The Clinical Teacher, 5, 23-27.

Kennedy, T. J., Regehr, G., Baker, G. R., \& Lingard, L. A. (2009). 'It's a cultural expectation...' The pressure on medical trainees to work independently in clinical practice. Medical Education, 43(7), 645-653.

Kirkpatrick, D. L. (1994). Evaluating training programs. San Francisco: Berrett-Koehler Publishers, Inc. 
Lave, J., \& Chaiklin, S. (1993). Understanding practice: Perspectives on activity and context. Cambridge: University of Cambridge Press.

Lave, J., \& Wenger, E. (1990). Situated learning: Legitimate periperal participation. Cambridge, UK: Cambridge University Press.

Marrow, C. E., \& Tatum, S. (1994). Student supervision: Myth or reality? Journal of Advanced Nursing, 19(6), 1247-1255.

Marton, F. (1986). Phenomenography-A research approach investigating different understandings of reality. Journal of Thought, 21(2), 28-49.

Marton, F., \& Saljo, R. (1997). Approaches to learning. In F. Marton, D. J. Hounsell, \& N. J. Entwistle (Eds.), The experience of learning (2nd ed., pp. 39-58). Edinburgh, UK: Scottish Academic.

Mattick, K., \& Knight, L. (2007). High-quality learning: Harder to achieve than we think? Medical Education, 41(7), 638-644.

Mattick, K., \& Knight, L. (2008). The importance of vocational and social aspects of approaches to learning for medical students. Advances in Health Sciences Education Theory Practice, 14(5), 629-644.

McKeachie, W. J. (1990). Research on college teaching: The historical background. Journal of Educational Psychology, 82, 189-200.

McParland, M., Noble, L. M., \& Livingstone, G. (2004). The effectiveness of problem-based learning compared to traditional teaching in undergraduate psychiatry. Medical Education, 38(8), 859-867.

Meyer, J. H. F. (1991). Study orchestration: The manifestation, interpretation and consequences of contextualised approaches to studying. Higher Education, 22, 297-316.

Meyer, J. H. F. (2000). Variation in contrasting forms of "memorising" and associated observables. British Journal of Educational Psychology, 70, 163-176.

Miller, G. E. (1990). The assessment of clinical skills/competence/performance. Academic Medicine, 65, 63-67.

Newble, D. I., \& Clarke, R. M. (1986). The approaches to learning of students in a traditional and in an innovative problem-based medical school. Medical Education, 20(4), 267-273.

Norton, L. (2004). Using assessment criteria as learning criteria: A case study in psychology. Assessment and Evaluation in Higher Education, 29(6), 687-702.

Papinczak, T. (2009). Are deep strategic learners better suited to PBL? A preliminary study. Advances in Health sciences Education: Theory and Practice, 14(3), 337-353.

Phillips, J. (1996). How much is the training worth? Training and Development, 50(4), 20-24.

Polit, D. F., \& Beck, C. T. (2003). Analyzing qualitative data. In Nursing research: Priciples and methods (pp. 430-439). Philadelphia: Lipincott.

Pramling, I. (1990). Learning to learn: A study of Swedish preschool children. New York: Springer.

Ramsden, P., \& Entwistle, N. J. (1981). Effects of academic departments on students' approaches to studying. British Journal of Educational Psychology, 51, 368-383.

Reid, W. A., Duvall, E., \& Evans, P. (2005). Can we influence medical students' approaches to learning? Medical Teacher, 27(5), 401-407.

Richardson, J. T., Dawson, L., Sadlo, G., Jenkins, V., \& McInnes, J. (2007). Perceived academic quality and approaches to studying in the health professions. Medical Teacher, 29(5), el108-el116.

Ritchie, J., \& Spencer, L. (1994). Qualitative data analysis for applied policy research. In A. Bryman \& R. Burgess (Eds.), Analyzing qualitative data. London: Routledge.

Schmeck, R., Ribich, F., \& Ramanaiah, N. (1977). The development of a self-report inventory for assessing individual differences in learning processes. Applied Psychological Measurement, 1, 413-431.

Schmidt, H. G., Cohen-Schotanus, J., van der Molen, H. T., Splinter, T. A. W., Bulte, J., Holdrinet, R., et al. (2010). Learning more by ebting taught less: A "time-for-self-study" theory explaining curricular effects on graduation rate and study duration. Higher Education, 60(3), 287-300.

Seabrook, M. A. (2003). Medical teachers' concerns about the clinical teaching context. Medical Education, $37,213-222$.

Svensson, L. (1997). Theoretical foundations of phenomenography. Higher Education Research and Development, 16(2), 159-171.

Van Lohuizen, M. T., Kuks, J. B. M., van Hell, E. A., Raat, A. N., \& Cohen-Schotanus, J. (2009). Learning strategies during clerkship and their effects on clinical performance. Medical Teacher, 31, e494-e499.

Vermunt, J. D. (1989). The interplay between internal and external regulation of learning, and the design of process-oriented instruction. Paper presented at the Paper presented at the 3rd Conference of the European Association for Research on Learning and Instruction.

Vermunt, J. D. (1996). Metacognitive, cognitive and affective aspects of learning styles and strategies: A phenomenographic analysis. Higher Education, 31, 25-50.

Vermunt, J. D. (1998). The regulation of constructive learning processes. British Journal of Educational Psychology, 68, 149-171. 
Wenger, E. (1998). Communities of practice learning, meaning, and identity. Cambridge, UK: Cambridge University Press.

Wimmers, P. F., Schmidt, H. G., \& Splinter, T. A. W. (2006). Influence of clerkship experiences on clinical competence. Medical Education, 40, 450-458. 